\title{
Interoperable Infrastructure for Flood Monitoring: SensorWeb, Grid and Cloud
}

\author{
Nataliia Kussul, Dan Mandl, Karen Moe, Jan-Peter Mund, Joachim Post, Andrii Shelestov, Sergii Skakun, \\ Joerg Szarzynski, Guido Van Langenhove, and Matthew Handy
}

\begin{abstract}
The paper presents an international multi-disciplinary initiative, a Namibia SensorWeb Pilot Project, that was created as a testbed for evaluating and prototyping key technologies for rapid acquisition and distribution of data products for decision support systems to monitor floods. Those key technologies include SensorWebs, Grids and Computation Clouds. This pilot project aims at developing an operational trans-boundary flood management decision support system for the Southern African region to provide useful flood and water-borne disease forecasting tools for local decision makers. This effort integrates space-based and ground sensor data along with higher level geospatial data products to enable risk assessment and ultimately risk maps related to flood disaster management and water-related disease management. We present an overall architecture of the Pilot along with components and services being developed. Additionally, case-studies and results achieved so far are discussed. The presented work is being carried out within GEO 2009-2011 Work Plan as CEOS WGISS contribution.
\end{abstract}

Index Terms-Earth observation, remote sensing, floods, sensor web, risk analysis, Grid, cloud computing, GEOSS.

\section{INTRODUCTION}

$\mathbf{U}$ NDERSTANDING the Earth system, its weather and climate, and natural and human-induced hazards, is crucial to enhancing human health, safety and welfare. When disasters strike, rapid access to data on local conditions, including roads,

Manuscript received September 30, 2011; revised January 31, 2012; accepted March 12, 2012. The work done at the Space Research Institute NASU-NSAU was supported in part by the U.S. Civilian Research and Development Foundation (CRDF) Grant UKB2-2972-KV-09.

N. Kussul is with the Space Research Institute NASU-NSAU, Kyiv, Ukraine (corresponding author, e-mail: inform@ikd.kiev.ua).

D. Mandl is with the NASA Goddard Space Flight Center, USA (e-mail: daniel.j.mandl@nasa.gov).

K. Moe is with the Earth Science Technology Office for the National Aeronautics and Space Administration (NASA), Goddard Space Flight Center, USA (e-mail: karen.moe@nasa.gov).

J. P. Mund is with the Department of GIS and Remote Sensing, University for Sustainable Development in Eberswalde (HNEE), Germany (e-mail: Jan-Peter. Mund@hnee.de).

J. Post is with the German Remote Sensing Data Center, German Aerospace Center (DLR), Oberpfaffenhofen, Germany (e-mail: Joachim.Post@dlr.de).

A. Shelestov is with the Space Research Institute NASU-NSAU, Kyiv, Ukraine (e-mail: andrii.shelestov@gmail.com).

S. Skakun is with the Space Research Institute NASU-NSAU, Kyiv, Ukraine (e-mail: serhiy.skakun@ikd.kiev.ua).

J. Szarzynski is with the Institute for Environment and Human Security (UNU-EHS), United Nations University, Bonn, Germany (e-mail: szarzynski@ehs.unu.edu).

G. Van Langenhove is with Hydrological Services Namibia, Department of Water Affairs, Namibian Ministry of Agriculture, Water and Forestry (MAWF), Windhoek, Namibia (e-mail: LangenhoveG@mawf.gov.na).

M. Handy is with the National Aeronautics and Space Administration (NASA), Goddard Space Flight Center (GSFC), USA (e-mail: matthew.handy@nasa.gov).

Digital Object Identifier 10.1109/JSTARS.2012.2192417 hospitals, population centers, weather forecasts and other information can help save lives. In 2002, the Global Earth Observation System of Systems, or GEOSS, was initiated to provide a global forum to improve Earth monitoring and predictions of Earth system behavior. GEOSS aims to strengthen analysis and decision making for disaster response and risk reduction by integrating different types of disaster-related data and information from diverse sources. GEOSS relies on the international Committee on Earth Observation Satellites (CEOS), to coordinate civil space-borne observations of the Earth. The SensorWeb approach [1]-[8] envisions the coordinated use of Earth observation data from both international satellite systems and regional systems, and their corresponding geospatial products and services to implement GEOSS functions in support of natural disasters.

Disaster management agencies all over the world have to adapt to an increasing number of natural disasters in particular caused by floods and drought. This paper describes an international multi-disciplinary initiative, titled Namibia SensorWeb Pilot Project, which aims at developing an operational trans-boundary flood management decision support system for the Southern African region to provide useful flood information and water-borne disease forecasting tools for local decision makers. The project represents a testbed for evaluating and prototyping key technologies for efficiently and rapidly acquiring and distributing relevant data products via the use of SensorWebs, Grids and computation clouds.

The Pilot Project was established under the auspices of the Namibian Ministry of Agriculture, Water and Forestry (MAWF) Department of Water Affairs, and the Committee on Earth Observing Satellites (CEOS)-Working Group on Information Systems and Services (WGISS), and was facilitated by the United Nations Platform for Space-based Information for Disaster Management and Emergency Response (UN-SPIDER). The effort consists of enlisting key partners that can provide satellite data and data product expertise, such as hydrological modeling, working with the Hydrological Services Namibia as a starting point to build a pathfinder system. The goal of the preliminary system was to put into place a few functional components that provide value added information to the decision makers in Namibia and thus offering a springboard to further expansion of the system to additional functionality and involving other partner countries in the region. The challenge in assembling this project was and still is the voluntary contributions of all organizations involved. There is no central funding organization and so anything that is built and maintained has been accomplished on a continuing voluntary basis. Because the effort is an international effort, the partners have worked under the umbrella of the GEO 2009-2011 Work Plan on the 


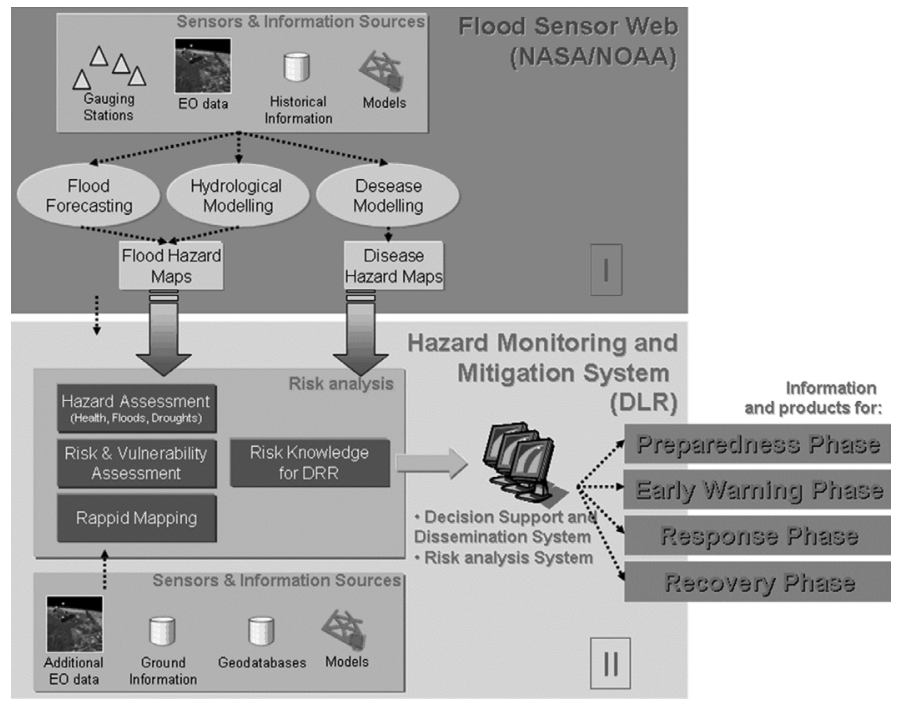

Fig. 1. Overview of proposed framework.

"Use of Satellites for Risk Management" as CEOS WGISS contribution. The following sections describe the generally accepted architecture, the phases of the pilot project and the challenges.

\section{Namibian Flood SensorWeb Pilot System: General ARCHITECTURE}

Like other regions on planet earth Sub-Sahara Africa has to deal with an increasing number of disasters nowadays. Especially within the Southern African Development Community (SADC) region disasters in terms of floods and droughts in close connection with water borne diseases play an important role.

The initial proposed system was described as an integrated Disaster Management System (DMS) to allow governmental and non-governmental organizations to easily access data related to changing conditions and resulting risk related data products and maps. The original proposed overall generalized architecture is shown in Fig. 1 and consists of two core components: a Flood SensorWeb and a Hazard Monitoring and Mitigation System.

The vision for the Pilot was to deploy this functionality as services using a virtual infrastructure. This means using web service standards following well accepted interfaces such as those developed by the Open Geospatial Consortium (OGC) and infrastructure defined by the Open Cloud Consortium (OCC).

\section{A. Flood SensorWeb}

1) SensorWeb Concept: SensorWeb is an emerging paradigm for integrating heterogeneous satellite and in situ sensors and data systems into a common informational infrastructure that produces products on demand. The basic functionality required from such an infrastructure includes sensor discovery, triggering events by observed or predicted conditions, remote data access and processing capabilities to generate and deliver data products. The Flood SensorWeb is implemented using the OGC Sensor Web Enablement (SWE) suite of web service protocols.
The initial rudimentary Flood SensorWeb developed for Namibia in 2010 aggregated relevant information for floods in version 1 of the system in a piecemeal fashion:

- The Tropical Rainfall Measuring Mission (TRMM) rainfall estimates and global flood potential forecast (provided by NASA) [9]. Rainfall estimates are 3-, 24-, 72- and 169hour rainfall accumulation. Flood potential forecasts are provided for 24-, 72- and 128-hour in advance. Real-time global estimation of flood areas using satellite-based rainfall and a hydrological model are run globally, every three hours at $0.25^{\circ}$ resolution. Real-time product are produced within $6 \mathrm{~h}$ after observations made by TRMM.

- EO-1 Advanced Land Imager (ALI) multispectral data (NASA) [4]. OGC Sensor Planning Service (SPS) is deployed for automatic tasking of EO-1 satellite within $8 \mathrm{~h}$ (re-image capabilities). Satellite images are available within 4-6 $\mathrm{h}$ after acquisition.

- Global Disaster Alert and Coordination System (GDACS) flood model data derived from Terra AMSR-E data (Joint Research Centre of the European Commission) [10], [11]. Daily flood magnitude time series are provided for any arbitrary observation point on Earth, with lag times as short as $4 \mathrm{~h}$. Spatial resolution is $8 \mathrm{~km} \times 12 \mathrm{~km}$.

- River gauge data (Hydrological Services Namibia).

- Namibia dwelling unit database.

- Coupled Routing and Excess STorage model (CREST) hydrological model (University of Oklahoma and NASA) [12]. The model provides global flood predictions at $1 / 8^{\circ}$ spatial resolution.

- Global daily Terra/Aqua MODIS flood extent maps at 250 $m$ resolution (Dartmouth Flood Observatory) [13].

- Malaria risk model (NOAA and City University of New York) [14], [15].

- Flood extent maps derived from synthetic-aperture radar instruments onboard Envisat/ASAR and Radarsat-2 satellites (Space Research Institute NASU-NSAU-SRI NASU-NSAU) [16]-[19]. The maps are provided on demand and delivered within $12 \mathrm{~h}$ after image acquisition. The services are run within the Grid infrastructure developed at SRI NASU-NSAU. The Grid infrastructure is described in the next section.

2) SensorWeb Operations: The operations concept of the initial Pilot was as follows:

1) During flood season, the Hydrological Services Namibia viewed the TRMM rainfall estimates in Angola.

2) Based on experience, strategically located river gauges located downstream are monitored via hydrographs which are daily rainfall and daily river heights overlaid on one graph and automatically updated.

3) The hydrographs which are time series graphs enabling hydrologists to monitor flood waves going downstream. Typically, heavy rains in Angola, translated to flood waves arriving in Namibia in 5-10 days.

4) When flood waves are in the process of travelling south to Namibia, satellite images are ordered to monitor the flood water progression. During year 2011, the key satellites used were EO-1 and Radarsat-2. 
5) In spring 2011, we used alerts from the GDACS system to automatically trigger EO-1 imagery when river widths in Angola as detected by AMSR-E were above a predetermined threshold.

6) Monitored output of the CREST model to see how well the initial model developed by University of Oklahoma could predict future river height levels.

7) Experiment with OpenID security to provide authentication of users on open Internet.

3) Lesson Learned and New Features: Having gained some initial experiences with gathering flood related data via the SensorWeb during the spring of 2010 and spring of 2011, lessons learned were folded into the development of version 2 of the Flood SensorWeb. Some of the lessons learned included:

- Need for improved correlation of EO-1 and Radarsat-2 calibration with ground conditions to more accurately detect water locations.

- Need for improved CREST model based on unique terrain characteristics in the basins in Namibia.

- Need for automated data product pipeline to eliminate many of the manual and semi-manual steps used in the initial pilot.

- Need for more flexible server to handle surge capacity and to handle large data sets efficiently.

- Automatic production of risk maps. In version 1, we did not produce any risk maps but rather focused on the mechanisms for capturing and distributing the relevant data.

Version 2 of the SensorWeb evolved included additions to address the lessons learned above. It has been an ongoing development process with target usage of the new functionality in spring 2012. The features added or in process of being added are:

- Store data, data products and displays (a portal) on Computation Cloud provided by OCC. OCC partnered with us in order to demonstrate the use of Clouds for disaster management. Experimenting with parallel processing by making use of multiple cores are run.

- Improved user displays.

- Additional steps in the processing chain such as the addition of atmospheric correction as a user select option of processing of satellite data

- Initiated effort to examine what elements needed to improve CREST model and thus make actual hydrographs match more closely with predicted hydrograph curve. Team plans to travel to Namibia to hold discussions with Hydrological Services Namibia.

- Better integration of SPS for triggering of multiple assets. When flood conditions are imminent via the use of software called GeoBPMS, the user specifies an area of interest and GeoBPMS returns the available satellite images, user can manually or automatically trigger tasking requests with data products coming back to the Cloud either in an automatic or semi-manual process.

- Develop more automated triggers for tasking and automated product generation.

- Integrate more satellites into the SensorWeb based on available partners.

- Increase usage of other OGC standards such as Sensor Observation Service (SOS), Web Coverage Service (WCS) and Web Feature Service (WFS) to provide easier access to data from the Cloud.

- Continue improving security by transferring OpenID security based software to the Cloud.

This functionality can be accessed through the Flood Dashboard display which described in Section IV.

\section{B. Hazard Monitoring and Mitigation System}

The second portion of the Namibia Flood Pilot was called the Hazard Monitoring and Mitigation System (HMMS) and was designed to provide higher level decision support information for disaster risk reduction. This functionality has not been implemented yet. Originally, the group outlined their vision of disaster response which consists of: pre-disaster phase (preparedness and awareness creation, development of adaptation and mitigation strategies, enhancement of disaster management capacities, evacuation and contingency planning); disaster phase (early warning $\&$ emergency relief); post-disaster phase (humanitarian aid, recovery). Since the amount of funding to create this portion of the Namibia SensorWeb pilot was large, the likelihood of immediate implementation was low.

It is anticipated, that as various SensorWeb lower level sensor data acquisition and distribution functionality is put into place, emergency workers will eventually need some help from the HMMS functionality to better perform their job.

Within the HMMS, a decision support and dissemination engine uses decision relevant information from risk analysis, rapid mapping and Flood SensorWeb information to provide early warning, emergency relief and recovery information to relevant institutions and communities.

\section{Matsu Cloud-Interim HMMS}

As an interim solution to an HMMS, OCC has contributed the Matsu Cloud which provides a large work area to collect flood related tools and data. Given that funding is at present not available for the entire HMMS as designed by the initial workgroup, the Matsu Cloud serves as a repository of data and tools that can be collected and used by the Hydrological Services Namibia for preliminary decision support exercises. Fig. 2 depicts the initial cloud configuration.

The key functionality added to this version of the Flood Dashboard is as follows:

1) Addition of a Web Coverage Processing (WCP) Service which enables users to customize how data is processed, including applying atmospheric correction as a data processing layer to EO-1 data.

2) Automated triggering of EO-1 imagery via triggers from the GDACS system based on upstream river widths.

3) Automated generation of EO-1 flood extent KML files to display on Google Maps (in process).

4) Store Radarsat-2 data on the cloud and experiment with parallel automated triggering of Radarsat-2 images.

5) Add dwelling unit database to show locations of buildings in areas prone to flooding.

6) Preliminary load balancing functionality to enable the use of parallel processing and the use of multiple virtual machines in the cloud to handle a surge of user demands. 


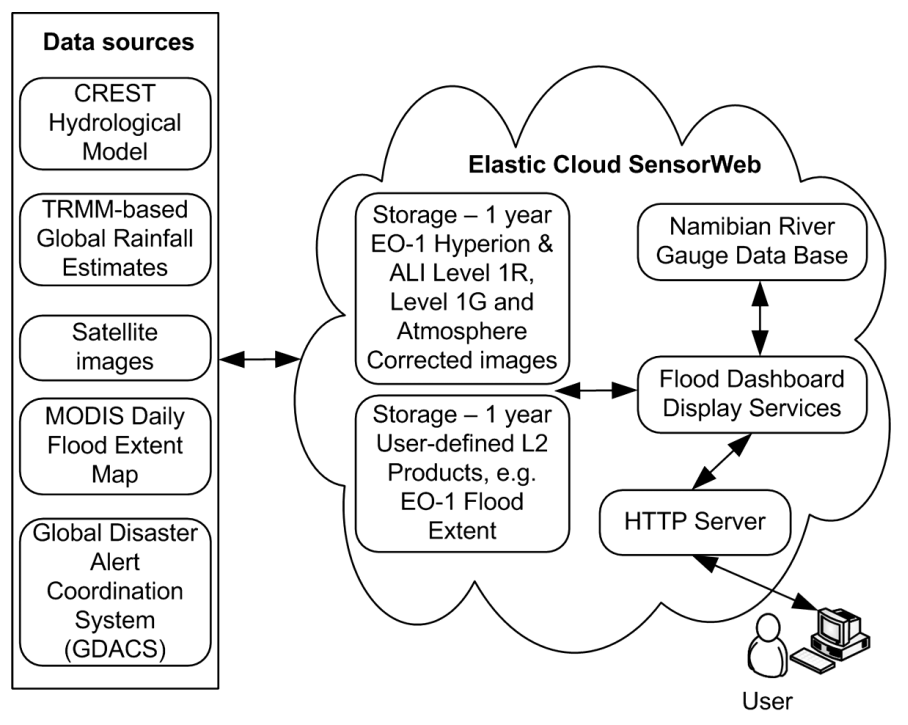

Fig. 2. Initial Matsu Cloud configuration.

The current configuration of the Cloud SensorWeb supplied by OCC is as follows: $300+$ core processors, 80 Tbytes of storage, $10 \mathrm{Gbps}$ connection to GSFC, Open Science Data Cloud (OSDC), a persistent, distributed storage and computing resource designed to manage, analyze, share, and archive scientific data [20], HTTP server to host the portal.

\section{GRID SYSTEM For Flood MAPPING BASED ON SATEllite SYNTHETIC-APERTURE-RADAR (SAR) IMAGERY}

This section further highlights a technical solution to rapid flood mapping from satellite imagery implemented within the Pilot. In particular, Grid technology is used to provide computational resources and enable automation and management of workflow for satellite data processing [16]-[19]. Currently, Grid infrastructure integrates the resources of several geographically distributed organisations:

- SRI NASU-NSAU (Ukraine) with deployed computing and storage nodes based on the Globus Toolkit 4 and gLite 3 middleware, access to data storage 10 Tbytes,

- Institute of Cybernetics of NASU (IC NASU, Ukraine) with deployed computing and storage nodes based on Globus Toolkit 4 middleware and access to computing resources (SCIT-1/2/3 clusters with $800+$ core processors),

- CEODE-CAS (China) with deployed computing nodes based on gLite 3 middleware and access to geospatial data (approximately 16 core processors).

\section{A. Overall Architecture}

Within the Grid infrastructure an automated workflow of satellite SAR data acquisition, processing and visualization, and corresponding geospatial services for flood mapping from satellite SAR imagery is implemented. The data are automatically downloaded from ESA rolling archives where satellite images are available within $2-4 \mathrm{~h}$ after their acquisition. Both programming and graphical interfaces were developed to enable search, discovery and acquisition of data. Within the Namibian Pilot the requests are submitted through pro- gramming interfaces to check for available data and initiate workflow execution.

Through the portal a user can perform a search for the SAR image file based on geographical region and a time range. A list of available SAR imagery is returned and the user can select a file in order to generate a flood map. The file is transferred to the resources of the Grid system at the SRI NASU-NSAU, and a workflow is automatically generated and executed on the resources of the Grid infrastructure.

A set of services has been implemented to enable execution of the workflow in the Grid environment. The four major components of the Earth System Grid compliant system [21] are as follows:

1) Client applications. Web portal functions as a main entry point, and provides interfaces to communicate with system services.

2) High-level services. This level includes security subsystem, catalogue services, metadata services (description and access), automatic workflow generation services, and data aggregation, sub-setting \& visualization services. These services are connected to the Grid services at the lower level.

3) Grid services. These services provide access to the shared resources of the Grid system, access to credentials, file transfer, job submission and management.

4) Database and application services. This level provides physical data and computational resources of the system.

\section{B. Grid Workflow of Flood Mapping From Satellite SAR Imagery}

A neural network approach to SAR image segmentation and classification was developed [22]-[24].

To benefit from the use of the Grid a parallel version of the method for flood mapping from satellite SAR imagery was implemented for parallelization of image processing according the subsequent process: a SAR image is split into the uniform parts that are processed on different nodes using the OpenMP Application Program Interface (www.openmp.org) [18]. The use of the Grids allowed us to considerably reduce the time required for image processing and service delivery. In particular, it took approximately more than $1.5 \mathrm{~h}$ (depending on image size) to execute the whole workflow on a single workstation. The use of Grid computing resources allowed to reduce the computational time to less than 20 minutes.

\section{NAmibian Flood SensorWeb Pilot Portal}

A project web site that provides general information on the Pilot was established, and is accessible at http://sensorweb.nasa.gov/NamibiaFlood.html. Near real-time products and a 2 year data product archive of the Pilot were integrated within the portal (Flood Dashboard) accessible at http://matsu.opencloudconsortium.org/namibiaflood (Fig. 3).

The portal and a part of computations associated with the Pilot were put onto clouds supplied by OCC. Combining SensorWebs with an elastic computation cloud enables surge capacity for disasters by enabling parallel processing of various algorithms and other processes within the cloud. 


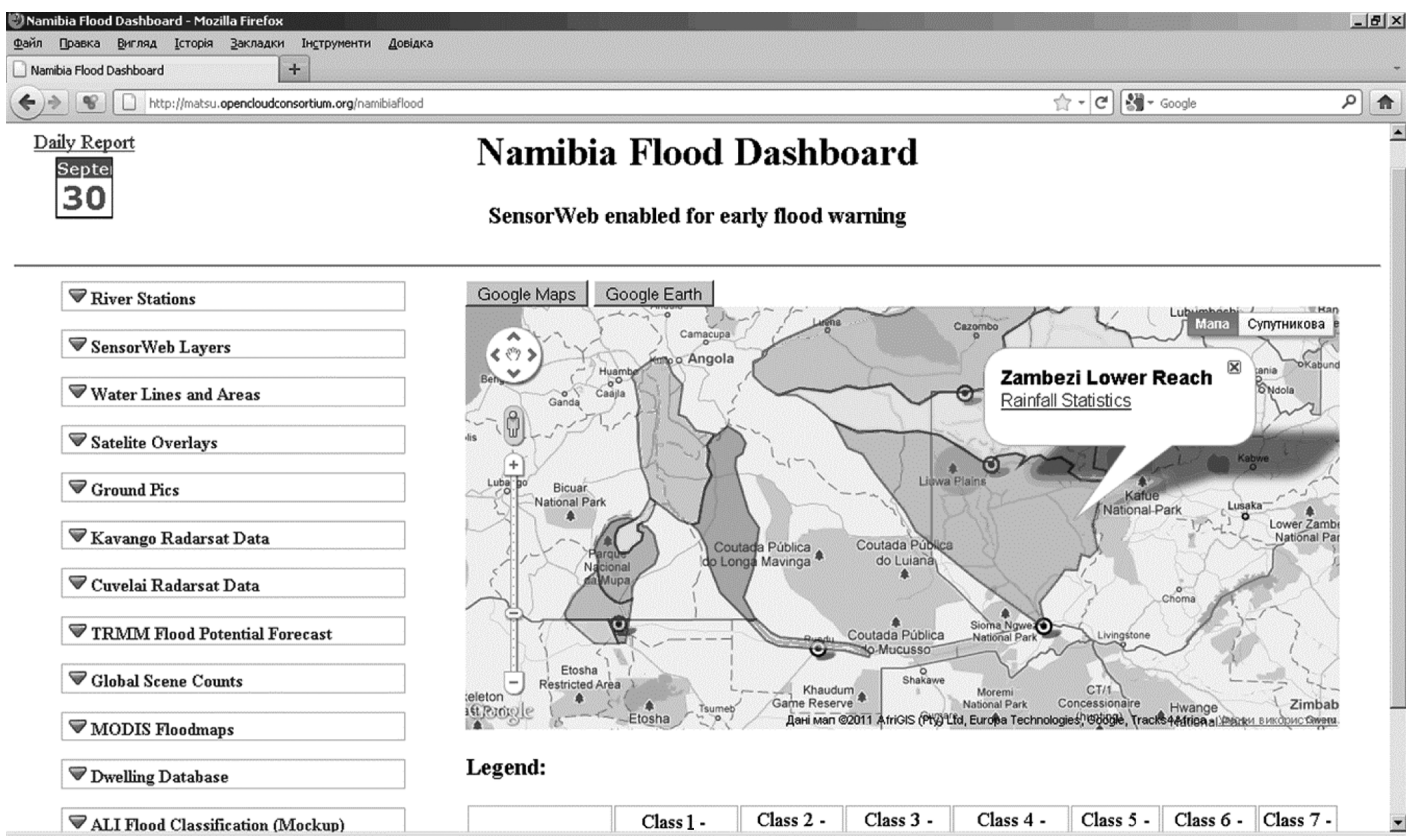

Fig. 3. Sensor Web Pilot portal that integrates near-real time and archive products.

The following datasets and products are available from the portal:

- Modeling data: the output of the CREST model, and GDACS system.

- Satellite data and products: TRMM-based global rainfall estimates and flood potential forecasts; flood extent maps derived from optical (MODIS on daily basis and EO-1/ALI on demand) and SAR images (Envisat/ASAR and Radarsat-2 on demand).

- Ground observations: water flow and level from river gauges; results of ground observations that were carried out in 2010 in order to validate satellite products and output of models.

The outputs of the models are used to generate alerts and trigger satellite data acquisition and generation of products that are further directed to end-users at Hydrological Services Namibia.

\section{CONCLUSION}

In this paper we presented an international multi-disciplinary initiative, a Namibia SensorWeb Pilot Project. The project represents a testbed for evaluating and prototyping key technologies for efficiently and rapidly acquiring and distributing relevant data products via the use of SensorWebs, Grids and computation clouds. The system provides access to real-time products on rainfall estimates and flood potential forecast derived from the TRMM mission (with lag time of $6 \mathrm{~h}$ ), alerts from the GDACS system (with lag time of $4 \mathrm{~h}$ ) and the CREST model to generate alerts. These are alerts are used to trigger satellite observations. With deployed SPS service for NASA's EO-1 satellite it is possible to automatically task sensor with re-image capability of less $8 \mathrm{~h}$. Therefore, with enabled computational and storage services provided by Grid and cloud infrastructure it was possible to generate flood maps within $24-48 \mathrm{~h}$ after trigger was alerted. Within the Pilot, we demonstrated the benefits of combining the sensor webs with emerging Grid and cloud computing technologies which enable workflow orchestration and parallel data processing on high-performance resources. To enable interoperability between system components and services OGC-compliant standards are utilized.

\section{REFERENCES}

[1] K. Moe, S. Smith, G. Prescott, and R. Sherwood, "Sensor web technologies for NASA Earth science," in Proc. 2008 IEEE Aerospace Conf., 2008, pp. 1-7.

[2] D. Mandl, S. W. Frye, M. D. Goldberg, S. Habib, and S. Talabac, "Sensor webs: Where they are today and what are the future needs?," in Proc. 2nd IEEE Workshop on Dependability and Security in Sensor Networks and Systems (DSSNS 2006), 2006, pp. 65-70.

[3] N. Kussul, A. Shelestov, and S. Skakun, "Grid and sensor web technologies for environmental monitoring," Earth Sci. Inf., vol. 2, no. 1-2, pp. 37-51, 2009.

[4] D. Mandl, "Experimenting with Sensor webs using earth observing 1," presented at the IEEE Aerospace Conf., Big Sky, MT, Mar. 2004.

[5] P. M. Teillet, "Sensor webs: A geostrategic technology for integrated earth sensing," IEEE J. Sel. Topics Appl. Earth Observ. Remote Sens., vol. 3, no. 4, pp. 473-480, 2010.

[6] S. S. Durbha, R. L. King, S. K. Amanchi, S. Bheemireddy, and N. H. Younan, "Standards-based middleware and tools for coastal sensor web applications," IEEE J. Sel. Topics Appl. Earth Observ. Remote Sens., vol. 3, no. 4, pp. 451-466, 2010.

[7] M. Moghaddam, D. Entekhabi, Y. Goykhman, L. Ke, L. Mingyan, A. Mahajan, A. Nayyar, D. Shuman, and D. Teneketzis, "A wireless soil moisture smart sensor web using physics-based optimal control: Concept and initial demonstrations," IEEE J. Sel. Topics Appl. Earth Observ. Remote Sens., vol. 3, no. 4, pp. 522-535, 2010.

[8] D. Liping, K. Moe, and T. L. van Zyl, "Earth observation sensor web: An overview," IEEE J. Sel. Topics Appl. Earth Observ. Remote Sens., vol. 3, no. 4, pp. 415-417, 2010.

[9] K. K. Yilmaz, R. F. Adler, Y. Tian, Y. Hong, and H. F. Pierce, "Evaluation of a satellite-based global flood monitoring system," Int. J. Remote Sens., vol. 31, no. 14, pp. 3763-3782, 2010.

[10] T. De Groeve, Z. Kugler, and G. R. Brakenridge, "Near real time flood alerting for the global distaser alert and coordination system," in Proc. 4th Int. ISCRAM Conf., B. VandeWalle, P. Burghardt, and C. Nieuwenhuis, Eds., Delft, The Netherlands, May 2007, pp. 33-40.

[11] T. De Groeve and P. Riva, "Global real-time detection of major floods using passive microwave remote sensing," in Proc. 33rd Int. Symp. Remote Sensing of Environment, Stresa, Italy, May 2009. 
[12] J. Wang et al., "The coupled routing and excess storage (CREST) distributed hydrological model," Hydrol. Sci. J., vol. 56, no. 1, pp. 84-98, 2011.

[13] G. R. Brakenridge and E. Anderson, "MODIS-based flood detection, mapping, and measurement: The potential for operational hydrological applications," in Proc. NATO Advanced Research Workshop Transboundary Floods, Oradea, Romania, May 4-8, 2005, p. 9.

[14] A. Rahman, F. Kogan, L. Roytman, M. Goldberg, and W. Guo, "Modelling and prediction of malaria vector distribution in Bangladesh from remote-sensing data," Int. J. Remote Sens., vol. 32, no. 5, pp. $1233-1251,2011$.

[15] A. Rahman, N. Krakauer, L. Roytman, M. Goldberg, and F. Kogan, "Application of advanced very high resolution radiometer (AVHRR)based vegetation health indices for estimation of malaria cases," Am. J. Trop. Med. Hyg., vol. 82, no. 6, pp. 1004-1009, 2010.

[16] G. Lecca, M. Petitdidier, L. Hluchy, M. Ivanovic, N. Kussul, N. Ray, and V. Thieron, "Grid computing technology for hydrological applications," J. Hydrol., vol. 403, no. 1-2, pp. 186-199, 2011.

[17] N. Kussul, A. Shelestov, and S. Skakun, "Grid technologies for satellite data processing and management within international disaster monitoring projects," in Grid and Cloud Database Management, S. Fiore and G. Aloisio, Eds. Berlin, Heidelberg: Springer-Verlag, 2011, pp. 279-306.

[18] N. Kussul, A. Shelestov, and S. Skakun, "Grid system for flood extent extraction from satellite images," Earth Sci. Inf., vol. 1, no. 3-4, pp. $105-117,2008$.

[19] A. Shelestov, N. Kussul, and S. Skakun, "Grid technologies in monitoring systems based on satellite data," J. Autom. Inf. Sci., vol. 38, no. 3, pp. 69-80, 2006.

[20] R. L. Grossman, Y. Gu, J. Mambretti, M. Sabala, A. Szalay, and K. White, "An overview of the open science data cloud," in Proc. 19th ACM Int. Symp. High Performance Distributed Computing, New York, NY, 2010, pp. 377-384.

[21] D. N. Williams et al., "Data management and analysis for the Earth system Grid," in J. Phys.: Conf. Ser., 2008, vol. 125, p. 012072.

[22] N. Kussul, A. Shelestov, and S. Skakun, "Flood monitoring on the basis of SAR data," in Use of Satellite and In-Situ Data to Improve Sustainability F. Kogan, A. Powell, and O. Fedorov, Eds., 2011, pp. 19-29, NATO Science for Peace and Security Series C: Environmental Security.

[23] S. Skakun, "A neural network approach to flood mapping using satellite imagery," Comput. Inf., vol. 29, no. 6, pp. 1013-1024, 2010.

[24] G. Ruecker et al., "Integration of remote sensing products in regional information systems to support decision making in land and water management in Central Asia," in GISCA '09 Bishkek, Conf. Proc., 2009.

Nataliia N. Kussul is Deputy Director and Head of Department of Space Information Technologies and Systems at the SRI NASU-NSAU, and Professor at the National Technical University of Ukraine "Kiev Polytechnic Institute". She received the Doctor of Sciences (second scientific degree) in applied mathematics from SRI NASU-NSAU in 2001, the Ph.D. degree in applied mathematics from the Institute of Cybernetics of NASU in 1991, and the M.S. degree with honors in mathematics from Kiev State University. Her current research interests include Grid computing, Sensor Web, intelligent computations, pattern recognition, remote sensing.

Daniel Mandl has been with NASA/Goddard Space Flight Center since 1980 and is the Mission Manager for the Earth Observing 1 (EO-1) mission since 2001 and the Principle Investigator for multiple research grants for SensorWebs since 2003. He led preliminary SensorWebs experiments in 2003 with delivery of rapid satellite data products for wildfires in collaboration with the U.S. Forest Service and later helped to establish collaborations with CEOS, UN-SPIDER, Centro del Agua del Trópico Humedo para America Latina y el Caribe (CATHALAC) in Panama, Regional Center for Mapping of Resources for Development (RCMRD) in Kenya, National Hydrological Services in Namibia and other groups to experiment with the use of SensorWebs to provide rapid satellite data products for flood detection, situational awareness and early warning. Recently, he has led efforts to build Flood SensorWeb capacity in Namibia towards an operational system and worked to add additional functional capacity with other satellites in the SensorWeb such as Radarsat.

Karen L. Moe is Manager of Technology Development for Sensor Webs at NASA's Earth Science Technology Office (ESTO) at the Goddard Space Flight Center. Her current responsibilities include defining and developing investment strategies for information technologies, i.e., acquiring, processing, storing and managing massive data resources for Earth science remote sensing projects. She has over 35 years experience with spacecraft command, control and data processing. She received the M.S.E.E. in computer engineering from the University of Maryland.

Jan-Peter Mund is Professor for GIS and Remote Sensing at the University of Eberswalde in Germany. Since 2010 he has also served as a senior advisor to the UN-Water Programme at the United Nations University in Bonn. From 2007 to 2010 he was a research scientist at the German Aerospace Centre (DLR) and from 2003 to 2007 he established a University Program on Land Management and Land Administration at the Royal University of Agriculture in Phnom Penh in Cambodia supported by the German Technical Cooperation (GIZ). He received the Ph.D. degree in physical geography and a German Diploma in geography, geomatics and landscape ecology. He gains more than 15 years of international experience in academic work, capacity building and applied remote sensing in Africa, Middle East and South East Asia. He is also a guest lecturer at German Universities for Remote Sensing, GIS and Disaster Management.

Joachim Post is a research scientist at the DFD and responsible for risk assessment research at DFD. He holds a diploma in environmental sciences from University of Trier (Germany) and a Ph.D. in geo-ecology from University of Potsdam (Germany) obtained while working for the Potsdam Institute for Climate Impact Research. He is an expert in environmental and natural hazards risk and vulnerability assessments, climate and land use change impacts on the environment and simulation modelling.

Andrii Yu. Shelestov is Leading Scientist at the SRI NASU-NSAU, Professor at the National Technical University of Ukraine "Kiev Polytechnic Institute", and Head of Department of Software Engineering at the National University of Life and Environmental Sciences of Ukraine. He received the Doctor of Sciences (second scientific degree) in information technologies from SRI NASUNSAU in 2009, the Ph.D. degree in applied mathematics from the Institute of Cybernetics of NASU in 1996, and the M.S. degree in information control and management from the NTUU "KPI" in 1992. His research interests include Grid computing, distributed systems, system architecture design.

Sergii V. Skakun is Senior Scientist at the SRI NASU-NSAU, and Associate Professor at the National Technical University of Ukraine "Kiev Polytechnic Institute". He received the Ph.D. degree in system analysis and theory of optimal solutions from the SRI NASU-NSAU in 2005, the M.S. degree with honors in applied mathematics from the Physics and Technology Institute of the NTUU "KPI". His research interests include Grid computing, Sensor Web, Earth observation, satellite data processing, and risk analysis.

Joerg Szarzynski received the diploma in geography from the University of Bonn, Germany, and the Ph.D. degree in physical geography and atmospheric sciences from the Universities in Mannheim and Göttingen. His professional career includes engagements with the Center for Development Research (ZEF) in Bonn and the German Aerospace Center (DLR) as well as UN-SPIDER. At the United Nations University Institute for Environment and Human Security (UNU-EHS) he is heading the section on Enhancing Graduate Educational Capacities for Human Security. As Educational Officer he is responsible for managing the UNU-EHS Ph.D. programme and training courses for graduate professionals. His research interests focus on environmental change and sustainable development research, geospatial technologies, early warning systems and disaster management, and innovative education concepts.

Guido Van Langenhove is the Head of the National Hydrological Services in Namibia. He received the B.Sc. (Hons.) degree in civil engineering from the University of Leuven, Belgium, in 1976. After a five-year stint with the Laboratory of Hydraulics there, he moved to Namibia and he has been with the National Water Affairs Department since then. His professional scope comprised hydrological monitoring, water resources modelling, operational hydrology and flood management. With the arrival of repeated major flood disasters in Namibia since 2008, this has increasingly included use of remote sensing for flood early warning and response systems.

Matthew Handy is a Software Engineer at NASA Goddard Space Flight Center. He received the B.S. degree in computer science from the University of Maryland in 2010. He supports the NASA EO-1 SensorWeb efforts in a software engineering capacity. 